\title{
Evaluation of Infrastructure Design Solutions Based on Traffic Modelling
}

\author{
Kristina Čiplyte, Saulius Vingrys, Rimvydas Sabonis \\ JSC “Kelprojektas”, Švitrigailos str. 11B, Vilnius 03228, Lithuania
}

\begin{abstract}
Nowadays the main task remains analysis of traffic flow. It is relevant for designing new roads or interchanges to evaluate the economic and environmental impacts. Foreign experience proves that traffic modelling software is being used before implementing modernization of road network. Traffic simulation models become more and more important tools ensuring traffic control and providing possibility to do the planning process of road network. The main goal of study is to create traffic simulation models using modern software which will enable efficient selection of road design solutions in Lithuania. During the research below studies traffic modelling software packages were analysed, traffic simulation models were designed using traffic modelling tools and calibration of traffic simulation models was made so as their adaptation to Lithuanian conditions. Traffic simulation models adapted to designing of road infrastructure and the process of selection of solutions. The results showed that road design solutions can be compared based on traffic simulation models. Thus a high level of design solutions is being ensured. Two Lithuanian study cases of using traffic modelling in infrastructure design projects are described in the article.
\end{abstract}

Keywords: Traffic modelling, Microsimulation, PTV VISSIM, Signal optimization.

\section{Introduction}

Traffic engineering tools like software used for macro and micro traffic modelling in Lithuania is being used more often with each year. Engineers working with complex streets and roads networks tend to use these tools to better understand the operations of the junctions and their effect on the analysed infrastructure. In this way economic and environmental parameters can be evaluated and bring benefit for people who use this network on a daily basis. It is proven that clients who decide to invest more in the complex projects and include traffic modelling to one of the design stages in a long lasting infrastructure buildings in the rational and intelligent way.

Due to the complexity of the traffic flow system, analytical approaches may not provide the desired results. Therefore, traffic flow (simulation) models designed to characterise the behaviour of the complex traffic flow system have become an essential tool in traffic flow analysis and experimentation [1].

In this article two study cases of applying traffic modelling tools in Lithuania are presented. First, is a suburban three level interchange close to Klaipeda. This interchange was designed when such tools were still not in use. Third and last stage of the Jakai interchange in Klaipeda is still not build and the evaluation and impact of the third stage solutions on current network is described in this article.

The second case study is a project of analysing the reorganization possibilities of traffic in Šiauliai. A case study focused on urban traffic and traffic light optimization.

\subsection{Application of traffic modelling}

Usually, when engineers make complex decisions for improving traffic situation, they rely on traffic modelling software which helps to forecast future traffic situation. This practice is applied across the world. The most popular traffic modelling programs are Aimsun, Quadstone Paramics and PTV Vissim [2-8].

For modelling of traffic in the Jakai interchange, German micro-simulation product PTV Vissim was chosen. It was developed by PTV AG as a package of transport modelling software. VISSIM uses invention by Rainer Wiedemann, a

Corresponding author: Saulius Vingrys. E-mail address: saulius.vingrys@kelprojektas.lt

http://dx.doi.org/10.3846/enviro.2014.115

(C) 2014 The Authors. Published by VGTU Press. This is an open-access article distributed under the terms of the Creative Commons Attribution License, which permits unrestricted use, distribution, and reproduction in any medium, provided the original author and source are credited. 
psychophysiological approach for drivers. The basic traffic model ruling the movement of vehicles was developed by in 1974 at Karlsruhe University. The application can analyse private and public transport operations under constraints such as lane configuration, vehicle composition, traffic signals, PT stops, etc., thus making it a useful tool for the evaluation of various alternatives based on transportation engineering and planning measures of effectiveness. Accordingly, pedestrian flows can be modelled, either separately or combined with private traffic and/or public transport [9].

The Wiedemann Car Following behavioural model in the VISSIM traffic modelling application was based on research carried out by Wiedemann in 1974. This model helps to assess the change of vehicle speed by taking into consideration the vehicles in front and includes the variation of driver conditions from free-flow speed and congested road network. The model assesses the relative distance of each vehicle and its speed in respect to other vehicles. According to Fellendorf and Vortisch [10], there are three stages of these actions, namely: free driving, approaching, following and stopping.

The first stage of the following vehicle's behaviour determines the driving of the vehicle in free mode, when focus on the manoeuvres of other vehicles is not required and only regulatory measures of the road have to be taken into consideration (such as controlled interchanges). Approaching usually refers to the act when the distance between vehicles is reduced and the vehicle driving behind detects the location of the leading one. If vehicles driving behind get near the vehicle driving in front of them, the ones that are falling behind react to the actions of the vehicles in front. Although the required safe distance to the leading vehicle remains, it continues to vary due to changes of speed - acceleration and deceleration. If the vehicle driving behind gets too close to the leading vehicle, the stopping stage begins. Accidents are most likely in this stage. VISSIM traffic simulation application is based on algorithms of two drivers' behaviour. The first algorithm was developed in 1974 (Wiedemann 74). Nowadays, it is still used when modelling city traffic. The second algorithm was introduced in 1999 and later on applied to highway conditions (Wiedemann 99). Both algorithms were used in the modelling process of traffic flows in the Jakai interchange: Wiedemann 74 algorithm for the roundabout and streets and Wiedemann 99 algorithm for overpasses in the Jakai interchange. Šiauliai city traffic was modelled with Wiedemann 74 algorithm.

\subsection{Traffic data collection and analysis}

The first task needed for the creation of the model is to collect and process the data representing the traffic volume. It is recommended that the hourly traffic volume which is used in traffic modelling should be the $30^{\text {th }}$ highest hourly volume of the year, abbreviated as $30 \mathrm{HV}$. The reasonableness of $30 \mathrm{HV}$ as a design control is indicated by the changes that result from choosing a somewhat higher or lower volume [11]. In Lithuania, no such practice is applied and data representing the distribution of traffic in interchanges are not recorded. As a matter of fact, in most cases traffic in complex junctions is analysed by using cameras. In nearly all cases, a practical and adequate time period is one hour [11].

The traffic in the Jakai interchange and Šiauliai city was filmed during the morning rush and during evening rush. Later, the footage was analysed and the volume of traffic in different sections of every direction was determined. In order to get more accurate traffic modelling results, one of three traffic assessment methods, described in the Highway Capacity Manual 2010 was selected [12].

\section{Case studies}

\subsection{Modelling of Jakai interchange III stage reconstruction}

The Jakai interchange is located in western Lithuania, near Klaipeda, the country's main seaport and the third biggest city with population of around 170,000. The interchange links Lithuania with Latvia. It mainly connects Klaipeda with Latvian seaports of Liepaja and Ventspils. Five roads intersect in the Jakai interchange. Here the main Lithuanian highway A1 Vilnius-Kaunas-Klaipedda meets another motorway A13 Klaipeda-Liepaja. Moreover, the city's free economic zone (FEZ) is located southwest of the interchange. Thus, the daily traffic volume of heavyweight vehicles is quite high. Transit vehicles come from and to the seaport of Klaipeda or go to a number of logistics terminals around the interchange in the FEZ. The amount of vehicles and the diversity of trips make the Jakai interchange one of the busiest and one of the most important interchanges in Lithuanian road network.

The preliminary design process began in 2004 and it was decided that the Jakai interchange reconstruction will be divided into three stages. Research of the intersection began in 2006, design was finished in 2008, and the first stage of the overpasses connecting Kaunas with Klaipeda and relieving the roundabout from the highest traffic volume was completed in 2010. In November 2012 the overpasses of second stage connecting Palanga with Kaunas were constructed. The purpose of these overpasses was to relieve the roundabout from the increasing summer traffic volume and to improve the level of service for drivers going on their holidays to Palanga. The third reconstruction stage was designed to connect Klaipeda to Palanga and Kaunas to Šilute. This case study focuses only on design and solutions for the III stage reconstruction of the interchange. When feasibility study of the reconstruction was done in 2006 traffic simulation software was not yet used in Lithuania, and solutions relied on the decisions of engineers and their long-term experience. With such micro-simulation tools as we have today the decision might have been different.

The study and the results of the article are not to be considered as finite and the reconstruction process of the interchange presented hereinafter can be different. In order to carry out this research as accurately as possible, not only it is necessary to carry out a detailed study of the Jakai interchange, but also to have the data on traffic in other Klaipeda's interchanges that 
make an impact on the traffic of the Jakai interchange. The analysis provides guidelines for the future research and describes one of the possible scenarios for the reconstruction of the Jakai interchange. For the purposes of modelling the traffic, the research was divided into three stages. Besides, premises determining the accuracy of the research were set. Stages of the research are as follows:

- Finding out whether the Jakai interchange needs the overpass Klaipėda-Palanga and Kaunas-Šilutè (third stage) by applying a traffic modelling application;

- Using the modelling of traffic to check the year when the overpasses (if necessary) should be built in order to avoid the traffic quality dropping to the lowest Level of Service F (LOS F);

- Checking whether or not to build the overpasses separately - constructing the first overpass (Kaunas-Klaipeda) and then the second (Kaunas - Šilutè).

Premises of the research are provided below:

- The growth of the traffic flow would not significantly differ from the forecasted growth on which the modelling of the traffic in the Jakai interchange was based;

- After opening Joniškès St. after the reconstruction, the street would take a part of traffic flow from the Jakai roundabout; it is expected that during rush hours, the number of vehicles taking Palanga-Klaipeda direction will decrease by 100-150 vehicles per hour;

- New popular sights would not redistribute the flows of traffic in Klaipeda and the traffic distribution would not differ from the distribution of traffic flows used in the modelling process.

Three morning and evening rush hour scenarios were modelled by:

- Leaving the interchange as it is;

- Building one overpass in direction Klaipeda-Palanga;

- Building two overpasses.

The period of the project was divided into five parts: 2013, 2015, 2020, 2025 and 2032. In total 30 models were created for the research. Each model was processed with 10 random runs of vehicle traffic combinations to make the results more accurate.

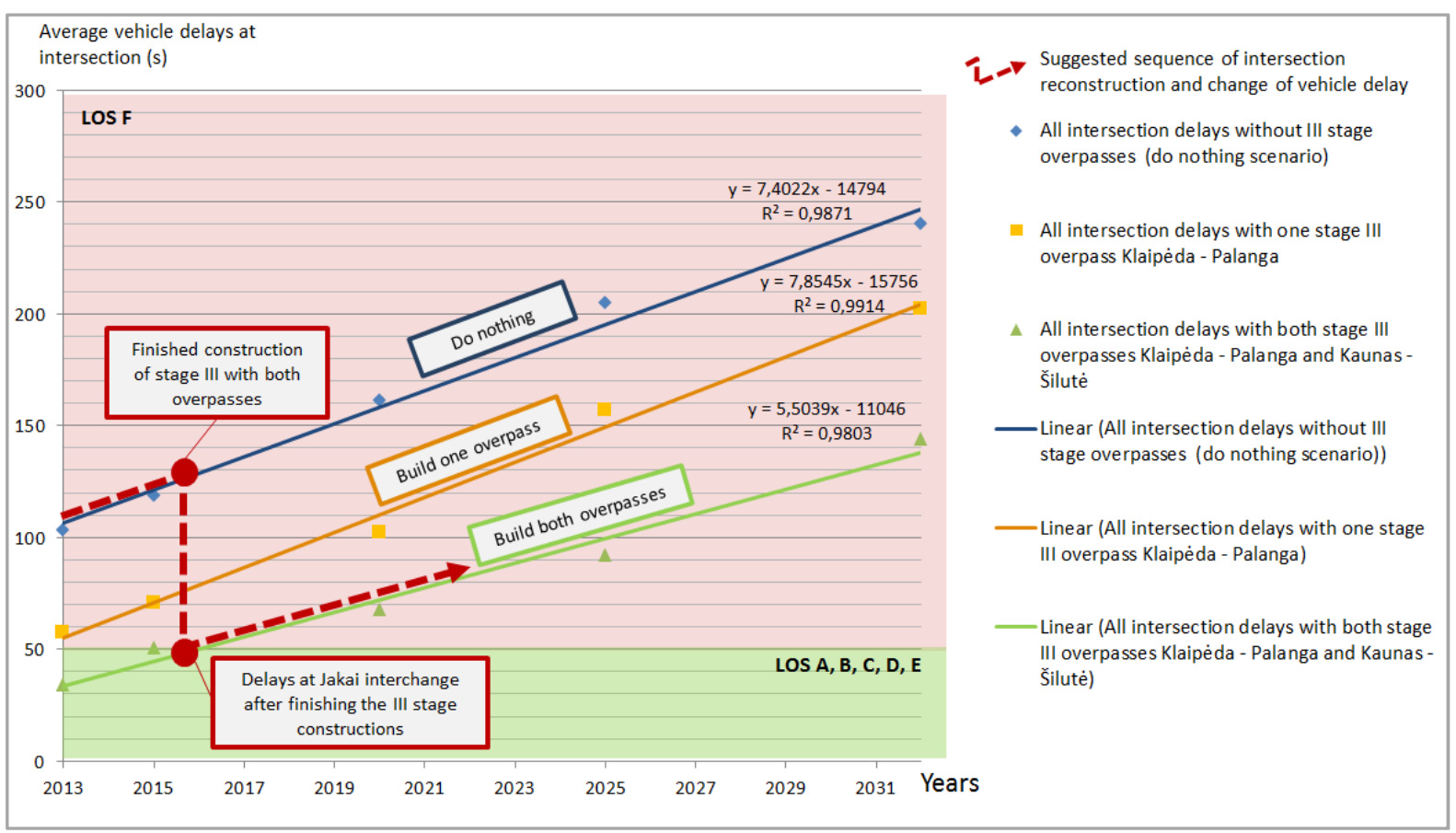

Fig. 1. Morning rush hour average delays at Jakai interchange (development of three possible scenarios)

The 2013 modelling of the traffic shows that the situation in the roundabout is slightly different from the assessment of traffic in 2012. The total average number representing the delay in morning rush hours in the roundabout accounts for 94 $\mathrm{s} /$ vehicle (LOS F), whereas in evening rush hours this number reaches $118 \mathrm{~s} /$ vehicle (LOS F). It should be noted that, in 2013, both the morning and evening rush hour delays were the same only on the Palanga entrance road. In the meantime, this number on other entrance roads varies depending on the time of the day - sometimes roads are loaded and the traffic is heavy and slow, whereas sometimes it does not take much time to enter the roundabout. The traffic model designed in 2013 showed that the ways to improve quality of traffic in the interchange are worth considering, since the index that reflects the quality of traffic in rush hours sometimes drops to the lowest level possible (LOS F). The lowest index of the quality of traffic both in morning and evening rush hours show that it is necessary to build overheard roads intended in the third stage. The analysis of the results also indicates that the situation of traffic will reach the desired level only if both overpasses are built (Fig. 1 and Fig. 2). According to the future modelling results, the biggest flow of vehicles will be from Šilute and 
Palanga directions. In addition, even if both overpasses are built, the index representing the quality of traffic in the interchange will fall to the LOS F level in 2018. The capacity of the interchange was the main parameter used in the research. The financial payback of the interchange was not considered regardless of the fact that it could influence the need to build new overpasses. The ecological aspect is also relevant. PTV VISSIM can help to calculate the amount of emission and fuel consumption, which also has a lot of impact on the payback of the third stage [13].

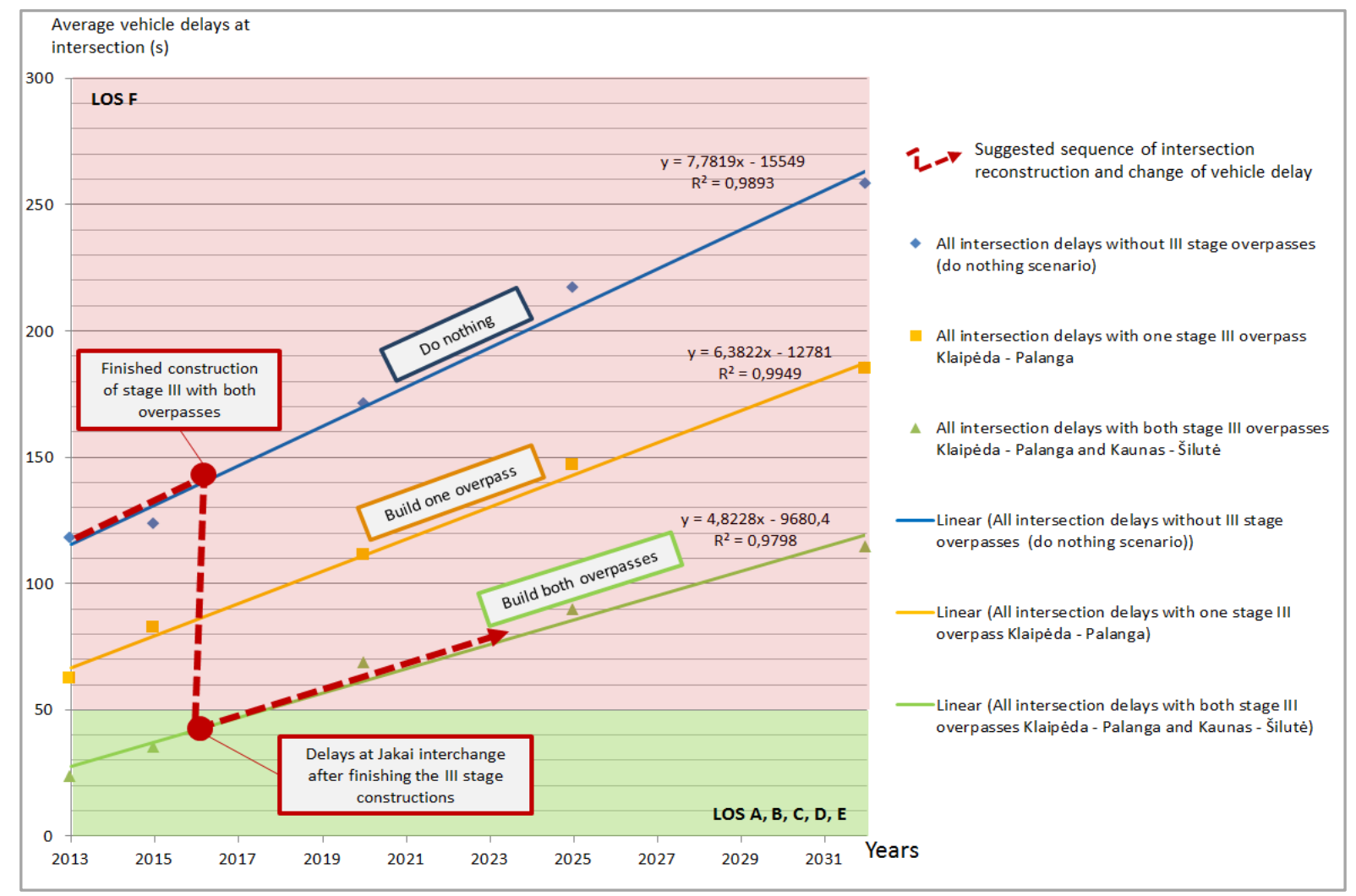

Fig. 2. Evening rush hour average delays at Jakai interchange (development of three possible scenarios)

\subsection{Modelling of Šiauliai city centre}

Project took place in the city Šiauliai which is located in northern part of Lithuania and has 110.000 inhabitants. Šiauliai is 5th biggest city in Lithuania and is a crossroad for important trans-European and national wide transport corridors. As shown in Figure 3 and 4 from south to west TEN-T IA corridor goes through Šiauliai. The city is also a crossroad for roads E77 and E272. Therefore, it was important to evaluate potential drawbacks of possible traffic changes [14].

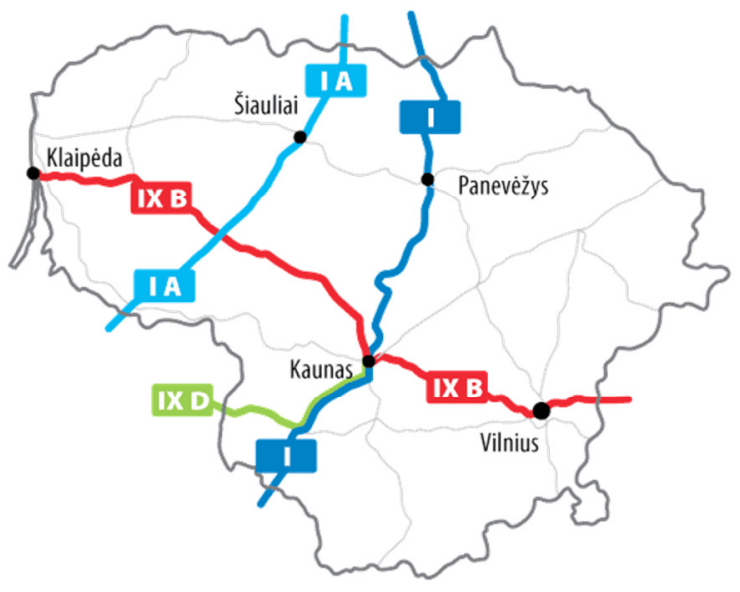

Fig. 3. TEN-T Trans European transport network corridors

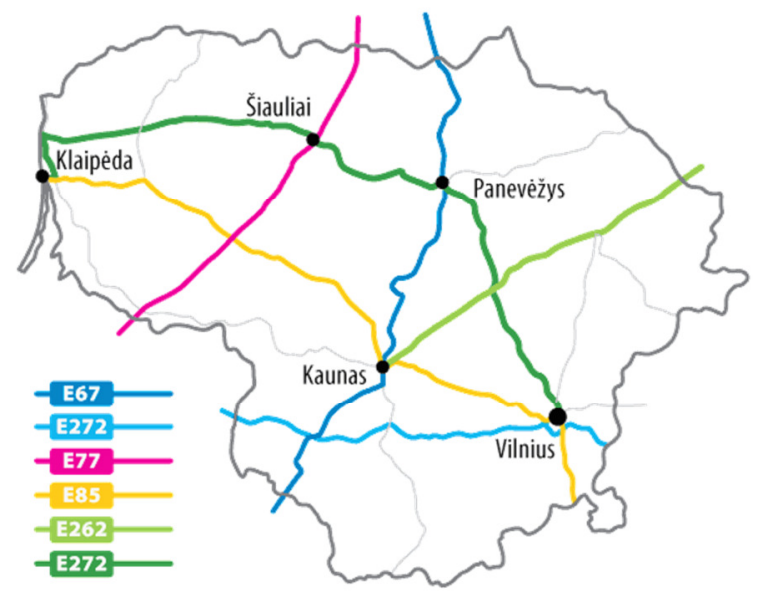

Fig. 4. E roads - has meaning for all Europe

Main goal of completed analysis was to determine influence for traffic in city centre when suggested traffic solutions would be implemented. As a main change in traffic organization was considered to be transforming one-way P. Cvirkos st. to two-way street. Also with intention to optimize traffic flows in Tilžès st. which is one of busiest streets of Šiauliai and is 
connected with P. Cvirkos st. by signalized intersection. While having main attention to mentioned problems, other affected surrounding areas have been also evaluated.

After evaluating city and street network four main traffic generating zones of the city were determined. Then scheme of traffic flow in corresponding zones of city was prepared. City zones and traffic flow chart are shown in Figure 5.

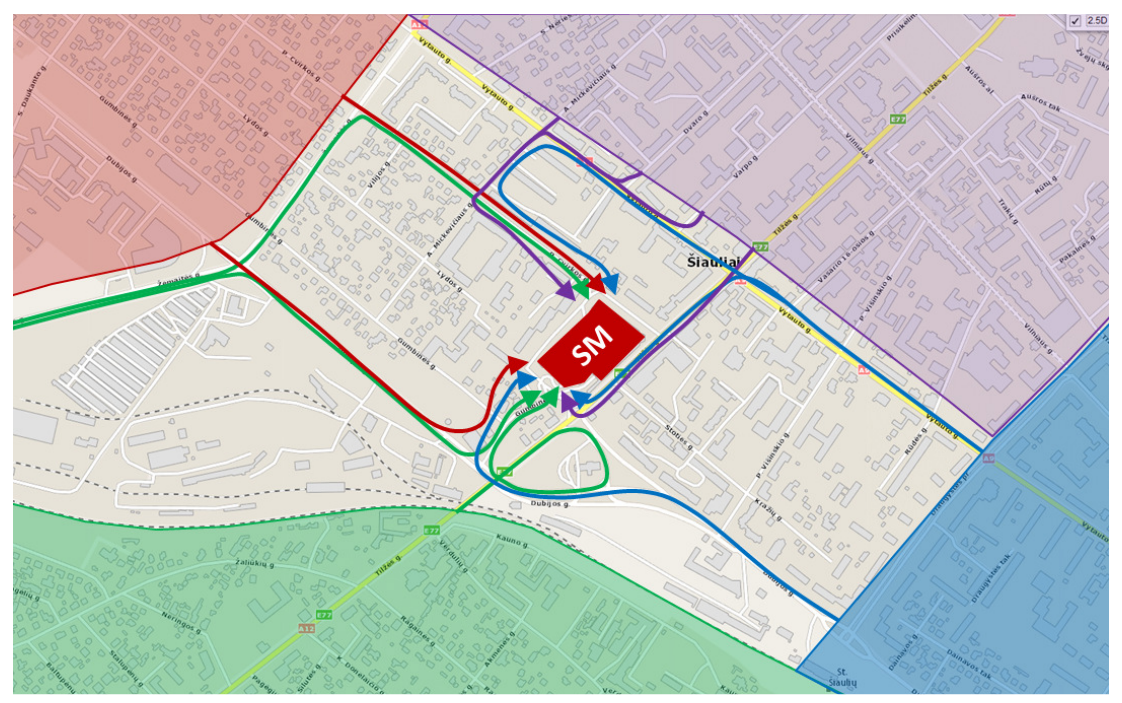

Fig. 5. City zones and traffic flow chart

That enabled engineers to identify junctions which had direct impact on the traffic in analysed area and where traffic had to be counted. After detailed traffic measurements origin-destination $(\mathrm{O} / \mathrm{D})$ matrix was generated with all traffic volumes in all measurement zones. Traffic volumes were prepared into morning and evening peak hours. To get full scale evaluation for solving the problem it was decided that 10 junctions had to be observed. To get accurate results all measurements were carried out three times in each particular position. After evaluating results it was determined that evening peak traffic flow volumes and saturation in streets are greater that in morning peak. This also showed that junctions where Tilžes st. meets P. Cvirkos St. and crosses Vytauto st. are very busy and during peak hours traffic jams are forming. All that information was the base for traffic modelling.

Before beginning modelling with software apart present situation two more scenarios were prepared. Both had similar base but deferent approaches.

I scenario: the goal was to design a traffic model with two-way traffic movement in P. Cvirkos st. from junction with Tilžès st. till entrance to the shopping center "Saulès miestas" (Fig. 6).

Advantages of current scheme:

- More convenient way to reach shopping center "Saulès miestas" from Tižès st. there would be no more need to use nearby streets.

Disadvantages of current scheme:

- In junction with Tilžès st. new traffic light phase needs to be implemented for left and right turning vehicles.

- After adding new phase adjacent traffic lights must be optimized and synchronized.

- By implementing new changes one of pedestrian crosswalks has to be removed because of new traffic regulations.

II Scenario: the goal was to design traffic model with two-way traffic movement in whole P. Cvirkos st. (Fig. 7).

Advantages of current scheme:

- More convenient way to reach shopping centre "Saulès miestas" from Tižès st. There would not be any need to use nearby streets.

- Enables other territories to be reached directly from Tilžès st.

- Because of two-way movement in whole street vehicles journey length will be reduced but that does not guarantee total journey time reduction in the network.

Disadvantages of current scheme:

- Due to newly opened two-way street, traffic from Tilžes st. to P. Cvirkos st. will increase. Therefore, traffic conditions might be less comfortable with higher delays.

- Also all mentioned problems from Scenario I remain in this scenario.

Traffic modelling was performed with PTV Vissim software. Detailed $1 \mathrm{~km}$ long and $750 \mathrm{~m}$ wide street network was created (Fig. 8). 


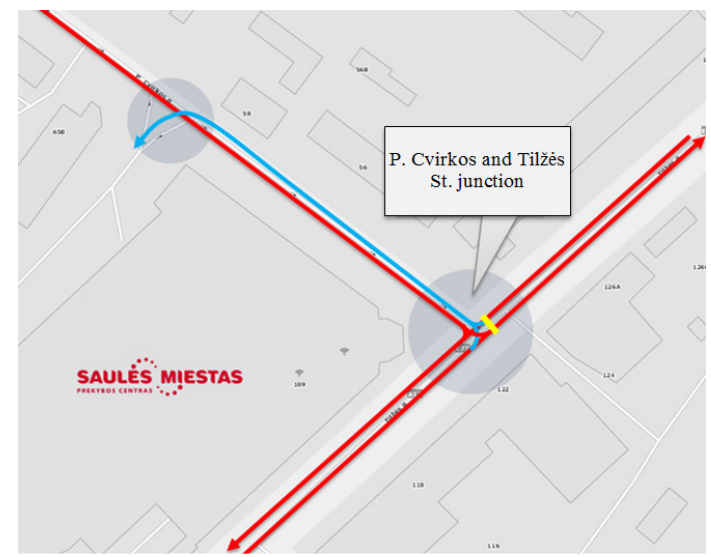

Fig. 6. Traffic movement scheme in scenario I

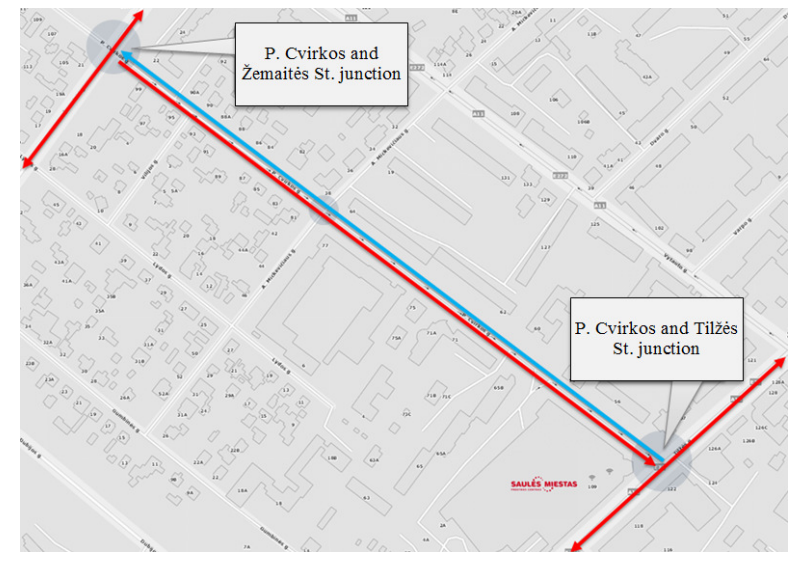

Fig. 7. Traffic movement scheme in scenario II

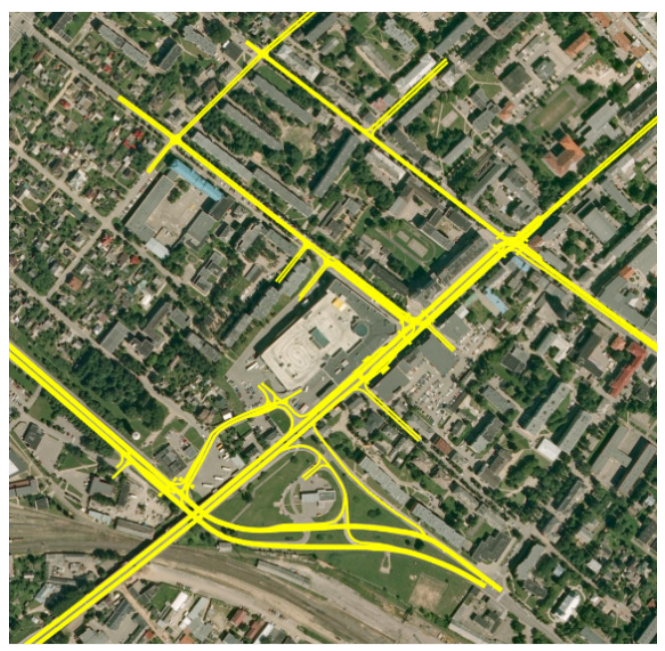

Fig. 8. street network created with PTV Vissim

Modelled network contained all major junctions and other important elements: pedestrian paths, bus stops and crosswalks. All traffic lights with their current cycles and phases were modelled.

Because of major changes in traffic movement, new phases and timings for traffic lights had to be set. That led to the need to optimize and synchronize adjacent traffic lights. Decision was made to synchronize those traffic lights to work as one system. For best performance green wave principle was suggested. Three traffic lights in main Tilžès st. were coordinated. Cycle and phases lengths with best performance were used during modelling (Figure 9). Modelling results were evaluated and final report was presented to stakeholders.

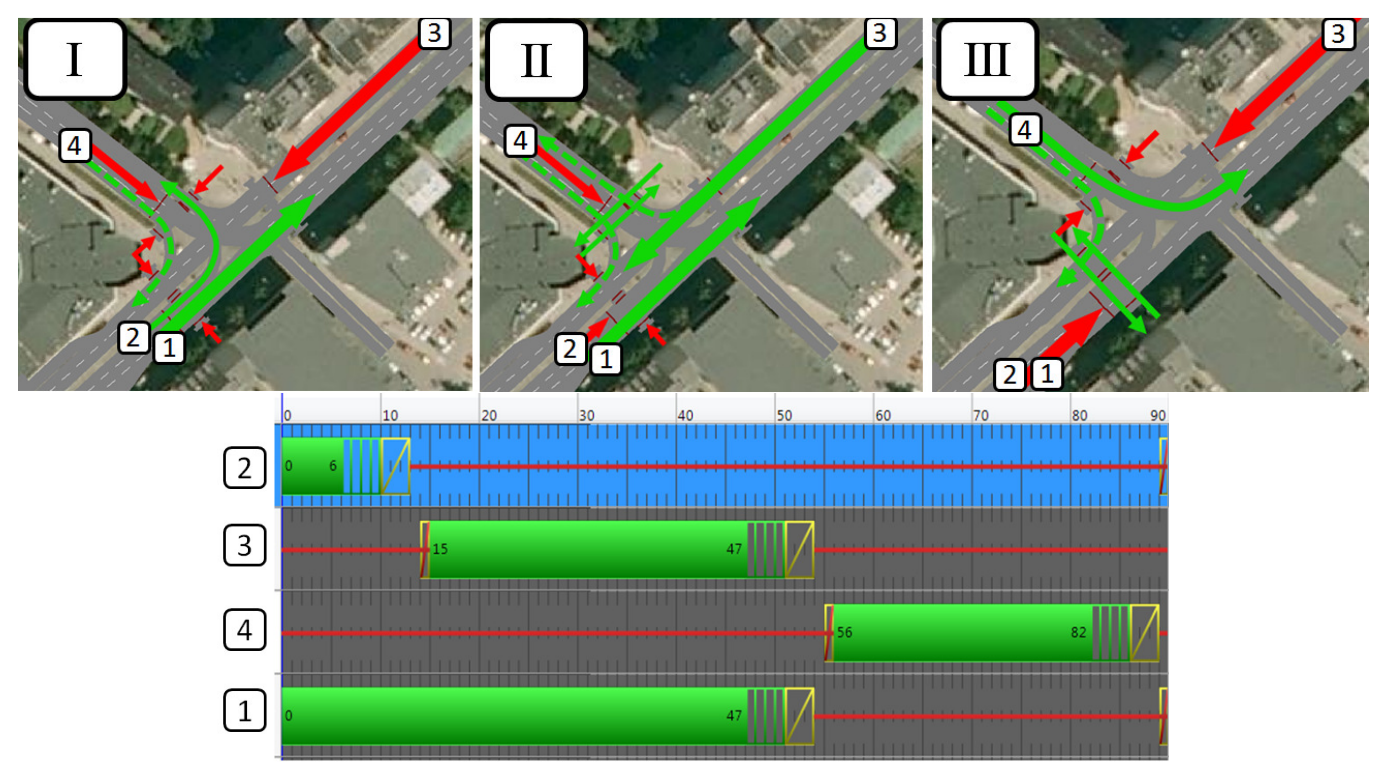

Fig. 9. P. Cvirkos and Tilžès St. suggested traffic light phases and timings 
The task of this project was to improve comfort of drivers and analyse if by transforming one-way street to two-way street we are able to achieve it. The biggest disadvantage and factor that was lowering the level of service of two-way street scenarios was the need of implementing an additional traffic light phase from Tilžès street to P. Cvirkos street. Modelling results showed that partial extension of the street to two-way street only up to the shopping centre (Scenario I) is not effective enough. The delays of such network is only slightly lower compared to a delay of the network where two-way street is extended fully till the next major junction (Scenario II). The Scenario I level of service was LOS B with 19,8 seconds of average delay per vehicle. The Scenario II level of service was LOS C with 20,2 seconds of average delay per vehicle. See Table 1.

Table 1. Comparison of modelling results

\begin{tabular}{|c|c|c|c|c|c|c|c|c|c|}
\hline Modelled options & 1 & 2 & 3 & 4 & 5 & 6 & 7 & 8 & $\begin{array}{l}\text { Average vehicle delay in the } \\
\text { network (s./veh.) and LOS }\end{array}$ \\
\hline \multirow{2}{*}{ Current situation } & 10,1 & 28,7 & 16,4 & 26,6 & 28,6 & 31,9 & 10,2 & 7,0 & 18,8 \\
\hline & B & $\mathrm{C}$ & B & $\mathrm{C}$ & $\mathrm{C}$ & $\mathrm{C}$ & B & $\mathbf{A}$ & B \\
\hline \multirow{2}{*}{ Scenario I (partial two-way street) } & 32,5 & 21,5 & 13,6 & 22,1 & 27,3 & 35,2 & 7,1 & 4,2 & 19,8 \\
\hline & $\mathrm{C}$ & $\mathrm{C}$ & B & $\mathrm{C}$ & $\mathrm{C}$ & D & A & $\mathbf{A}$ & B \\
\hline \multirow{2}{*}{$\begin{array}{c}\text { Scenario II (fully extended two- } \\
\text { way street) }\end{array}$} & 33,4 & 20 & 18,7 & 18,4 & 30 & 42 & 10,4 & 4,1 & 20,2 \\
\hline & $\mathrm{C}$ & B & B & B & $\mathrm{C}$ & D & B & $\mathbf{A}$ & $\mathrm{C}$ \\
\hline
\end{tabular}

While analyzing current situation it was observed that traffic lights are not working in an optimal way. Currently two closely situated intersections are working with different length signal cycle programs. Sometimes this forces drivers to stop twice at the intersections. Moreover, pedestrians are being mixed with left turning vehicles, blocking vehicles, disturbing their flow and reducing the capacity of the network.

Traffic light programs for both models (Scenario I and Scenario II) were changed and optimized. In addition, the unsafe pedestrian crossing close to the cross section Nr. 1 was removed. This improved traffic flow from P. Cvirkos towards the city center (from cross section Nr. 2 to Nr. 4) (see Fig. 10). These were the main reasons why both modelled options operated in almost similar quality as current situation. Besides the fact that in newly modelled scenarios at the intersection close to the supermarket an additional phase for left turners had to be implemented. These, above mentioned clauses, are the key for both scenarios to operate properly in reality as it was predicted in the models.

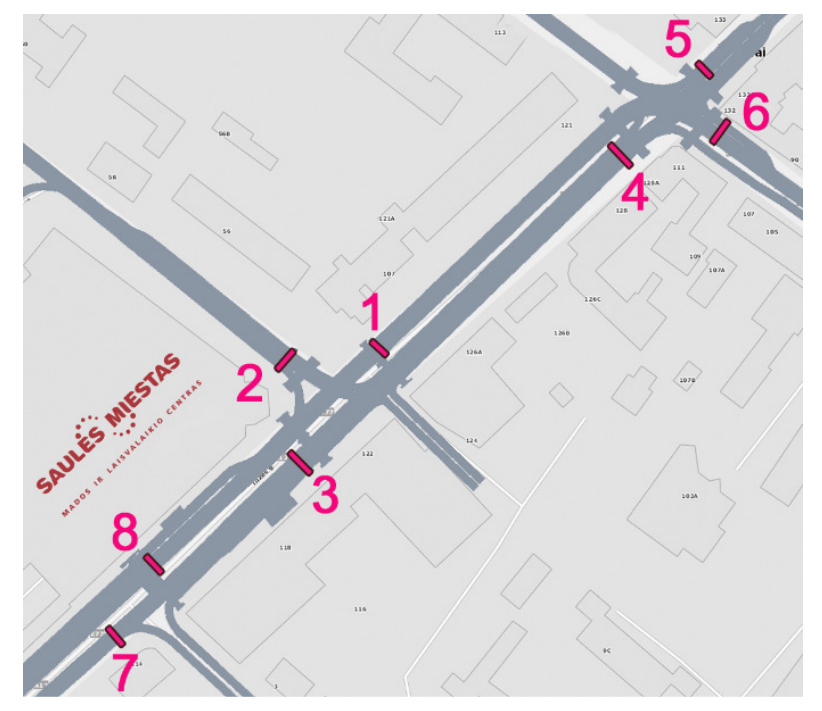

Fig. 10. Number and location of cross-sections used for evaluation network performance (see Table 1)

Traffic modelling of this project shows that P. Cvirkos street can be reconstructed to two-way street and not cause bigger traffic jams compared to the current situation. Drivers who reach their home through P. Cvirkos St. will be able to reach their destination faster. On the other hand, due to two-way street and additional traffic light phase drivers who use Tilžès street (main traffic volume) will lose additional time. That's why in our opinion the best solution in this situation would be to leave P. Cvirkos street as a one-way street and invest in the optimization of the traffic lights and elimination of dangerous zebra crossing.

\section{Conclusions}

In this article it is shown how successfully traffic engineers can identify the best solutions for particular situation by evaluating multimodal traffic problems. Both case studies prove that decision making of further infrastructure development is well justified and major doubts can be effectively solved. Therefore microscopic simulation can be a powerful and 
versatile tool but knowledge of calibrating these models is essential and can be a crucial to precision of results. It is very important to analyse current situation and create models closely reflecting existing situation and prevailing driving behaviour. Moreover, analysing already build projects which were modelled and evaluating situation on site can be useful for spotting mistakes and avoiding them in future projects.

Another important factor for assuring high quality models is traffic data collection. Though, it was not described in details in this article but traffic data was the base for both study cases. During times of limited resources and increasing political unwillingness to invest in new roads, traffic management becomes vital for increasing traffic operations. Lithuania still has not fully researched areas of non-intrusive traffic data collection systems. Therefor a possible use of Bluetooth detectors and ANPR cameras can be analysed for gathering traffic distribution data and creating more accurate O/D matrixes. Moreover, special radars and wireless detectors can be useful when evaluating traffic volume counts. By implementing these and other intelligent traffic systems tools traffic data would be gathered in bigger quantities and with higher precision creating a much needed data base for roads and streets network development.

In addition, as the majority of tools used in transport infrastructure design, traffic modelling software has to be used with proper approach and theoretical knowledge. The main piece in this process is still an engineer who makes decisions and adjusts the software for the needs of the project. That is why traffic engineering experience and acquired foreign expertise are also key factors for project quality.

\section{References}

[1] Hoogendoorn, S.; Bovy, P. 2001. State-of-the-art of vehicular traffic flow modelling, Journal of Systems and Control Engineering (4): $283-303$.

[2] Gao, Y. 2008. Calibration and Comparison of the Vissim and integration microscopic traffic simulation models. Virginia Polytechnic Institute and State University.

[3] Chowdhury, L. S.; Schadschneider, A. 2000. Statistical physics of vehicular traffic and some related systems, Physics Reports, 199-329. http://dx.doi.org/10.1016/S0370-1573(99)00117-9

[4] Hoogendoorn, S.; Daamen, W. 2007. Microscopic calibration and validation of pedestrian models: Cross-comparison of models using experimental data. In Schadschneider, A.; Pöschel, T.; Kühne, R.; Schreckenberg, M.; Wolf, D. editors, Traffic and Granular Flow 05: 329-340.

[5] Barcelo, J. 2001. Microscopic traffic simulation: a tool for the analysis and assessment of ITS systems, Highway Capacity Committee. Half year meeting. Lake Tahoe.

[6] Drummond, K.; Hoel, L.; Miller, J. 2002. Using simulation to predict safety and operational impacts of increasing traffic signal density, Transportation Research Record: 1784, Transportation Research Board, Washington.

[8] VISSIM Product Information [online]. Available from internet: http://mctrans.ce.ufl.edu/store/description.asp?itemID=662. Accessed January 20, 2014.

[9] Wiedemann, R. 1974. Simulation des straßenverkehrsflußes. Technical Report 8. Institute for Traffic Engineering, University of Karlsrühe, German.

[10] Fellendorf, M.; Vortisch, P. 2001. Validation of the microscopic traffic flow model VISSIM in different real-world situations, in Prceeings of the Transportation Research Board. Washington.

[11] The American Association of State Highway and Transportation Officials. 2011. A Policy on Geometric Design of Highways and Streets. Washington: $6^{\text {th }}$ edition. 103-106 p. ISBN: 978-1-56051-508-1.

[12] Transportation Research Board. 2010. Highway Capacity Manual. Transportation Research Board of the National academies. Volume 3: Interrupted flow. Chapter 17: 1-26. Washington, D. C.

[13] Vingrys, S.; Čiplytè, K.; Sabonis, R. 2013. Application of traffic modelling in transport infrastructure design: solving complex problems and improvingg effeciency of the Jakai interchange, in XXVIII International Baltic Road Conference. Vilnius.

[14] European Commission. 2006. Study on strategic evaluation on transport investment priorities under structural and cohesion funds for the programming period 2007-2013. Country Report Lithuania, No 2005.CE.16.0.AT.014. 